University of Nebraska - Lincoln

DigitalCommons@University of Nebraska - Lincoln

Economics Department Faculty Publications

Economics Department

2001

Differential Efficiency, Market Structure, and Price

Azzeddine Azzam

University of Nebraska-Lincoln, Aazzam1@unl.edu

David Rosenbaum

University of Nebraska-Lincoln, drosenbaum1@unl.edu

Follow this and additional works at: https://digitalcommons.unl.edu/econfacpub

Part of the Economics Commons

Azzam, Azzeddine and Rosenbaum, David, "Differential Efficiency, Market Structure, and Price" (2001). Economics Department Faculty Publications. 43.

https://digitalcommons.unl.edu/econfacpub/43

This Article is brought to you for free and open access by the Economics Department at DigitalCommons@University of Nebraska - Lincoln. It has been accepted for inclusion in Economics Department Faculty Publications by an authorized administrator of DigitalCommons@University of Nebraska - Lincoln. 


\title{
Differential Efficiency, Market Structure, and Price
}

\author{
Azzeddine Azzam ${ }^{a}$ and David Rosenbaum ${ }^{b}$ \\ ${ }^{\mathrm{a}}$ Department of Agricultural Economics and ${ }^{\mathrm{b}}$ Department of Economics, \\ University of Nebraska-Lincoln, Lincoln, Nebraska 68583-0922, USA \\ Email: aazzam1@unl.edu \& drosenbaum1@unl.edu
}

\begin{abstract}
A persistent question in industrial economics is the underpinning of the link between market concentration and price. How much of the link can be attributed to market power and how much to market efficiency? This paper develops a theoretical model to address that question. Applied to the US portland cement industry, the model indicates that both impacts matter. In relative terms, however, the market power effect is twice as large as the efficiency effect. An implication for merger policy is that the beneficial efficiency effects of mergers may not be obtained without the detrimental market power effects as well.
\end{abstract}

\section{Introduction}

The market power versus efficiency debate in industrial organization is well known. Proponents of the market power argument attribute the positive correlation between market concentration and profitability to collusion. Proponents of the efficiency argument assert the correlation reflects the superior efficiency of large firms. So, the causal direction is not from market power to higher profits, but from efficiency to higher profits and higher concentration (Demsetz, 1973).

Until recently, the predominant approach to resolve the conflicting interpretations has been to use cross-industry samples, and include both market share and concentration as determinants of firm profits. ${ }^{1}$ The presence of efficiency is taken to be associated with a positive and significant market share effect, that of collusion with a positive and significant concentration effect.

The approach has several limitations. First, how the two effects are exactly linked to profits is not clear from the regression. Second, even if one subscribes to the implied efficiency effect of market share, and to the implied collusion effect of concentration, when market share of the larger firms is highly correlated with concentration, it is difficult to discriminate between the collusion and efficiency hypotheses (Philips, 1976;
Kwoka, 1979; Clarke et al. 1984). Third, as Kardasz and Stollery (1995) have shown, in samples dominated by small firms, a negative coefficient on concentration supports rather than refutes the collusion hypothesis. Fourth, regression estimates of the two effects are not helpful in answering the fundamental question regarding the profitability-concentration relation. That is, how much of the correlation is due to efficiency and how much is due to collusion? Fifth, treatment of concentration as an exogenous variable does not accommodate the hypothesized link from greater efficiency to higher concentration.

Two tests which circumvent some of the limitations have recently been conducted at the single-industry level. Using estimates from a Bresnahan (1982) type conjectural oligopoly model, Rosenbaum (1994) inferred efficiency and collusion in the cement industry from changes over the sample period in marginal costs and price-cost margins, respectively. Azzam (1997) used a framework similar to Appelbaum's (1982) to separate the market-power effect of increased concentration in the beef-packing industry from its cost-efficiency effect. Unlike Rosenbaum, Azzam formally linked the collusion and efficiency components to industry concentration. However, neither study considered the link from efficiency to concentration.

\footnotetext{
${ }^{1}$ See for example Ravenscraft (1983).
} 
In this paper the link from concentration to collusion and efficiency, and the link from efficiency to concentration are formalized. In so doing, a way to testing Williamson's (1968) policy tradeoffs, and Demsetz's efficiency hypothesis is provided. The framework is a hybrid of Azzam's procedure for separating the market power effect from the cost-efficiency effect of industrial concentration, and Clarke and Davies' (1982) work on the joint determination of structure and performance.

The paper is in six sections. The next section briefly describes the portland cement industry which is used for empirical analysis. The theoretical model is developed in the third section. The model explicitly identifies the concentration-related market power and market efficiency components of price. It also creates a link between firm differential efficiency and market concentration. Section IV describes the empirical approximation of the theoretical model and discusses the data. Results are presented in Section V. These results unambiguously show that rising market power raises price while rising efficiency lowers price. The market power effect, however, is twice the magnitude of the efficiency effect. Hence, overall, increases in concentration increase price. The results also show that concentration is an increasing function of the variance in costs across firms in the market. The greater the cost variance, the more larger firms benefit at the expense of smaller firms and the higher the market concentration.

\section{The Portland Cement Industry}

Portland cement is a homogeneous producer good. Given its low ratio of value to weight, it is shipped limited distances. ${ }^{2}$ Consequently, the US supply of portland cement can be divided into a number of regional markets. Regional markets tend to have a limited number of suppliers. Buying patterns tend to exhibit frequent sales. Many firms are interconnected across regional markets. Previous studies have found evidence of behaviors consistent with tacit collusion in this industry. ${ }^{3}$

The portland cement production technology uses calcium carbonate rock which is crushed and then combined with lime and sand for grinding. Once ground, the raw materials are fed into a kiln where intense heat causes chemical changes in the composition of the feed stock. Kiln output, clinker, is then combined with gypsum and ground again. The end result is portland cement.

There are essentially five variable inputs into cement production: labor; fuel (predominantly coal or natural gas) which is used to heat the kiln and is the primary in- put expense; electricity, used to operate related auxiliary equipment; feed stocks; and maintenance. Furthermore, as variable inputs are not substitutable, the process exhibits a fixed factor production function. Marginal costs do vary across kilns, however, based on respective technologies, capacities and ages.

Portland cement is predominantly used in construction. Over the period 1978-1982, approximately 65\% of sales were for building construction, 31\% for highway construction, and less than $5 \%$ went towards nonconstruction activities. ${ }^{4}$ The demand for cement should be fairly inelastic since there are few substitutes and its cost makes up a moderate part of most construction projects. Note that asphalt is an alternative for some highway construction applications.

\section{The Model}

The starting point of the model is an industry consisting of $N$ firms producing a homogeneous output $Q$, and facing the inverse demand function

$$
p=p(Q, Z)
$$

where $p$ is price, and $Z$ is a vector of demand shifters. Assuming the objective of the $j$ th firm is to maximize profits

$$
p q_{j}-C_{j}\left(q_{j}, v\right)-F
$$

where $C_{j}$ is total cost, and $v$ is a vector of factor prices, then that firm's supply relation is

$$
p=q_{j}\left(1+\theta_{j}\right) / Q \eta^{2}+c_{j}\left(q_{j^{\prime}}, v\right)
$$

where $\eta=-(\mathrm{d} Q / \mathrm{d} p)(1 / Q)$ is the semi-elasticity, $\theta_{j}=\sum_{i \neq}^{N}$ $\left(\mathrm{d} q_{i} / \mathrm{d} q_{j}\right)$ is the $j$ th firm's conjectural variation, and $c_{j}\left(q_{j^{\prime}}\right.$ $v$ ) is marginal cost.

If, as in Azzam, the jth firm's cost function is assumed to take the Generalized Leontief (GL) (Diewert, 1971) functional form

$$
C_{j}\left(q_{j}, \nu\right)=q_{j} \sum_{i} \sum_{k} \alpha_{i k}\left(\nu_{i} \nu_{k}\right)^{1 / 2}+\left(q_{j}\right)^{2} \sum_{i} \beta_{i} \nu_{i}
$$

and all firms hold identical conjectures, multiplying both sides of Equation 3 by $q_{j} / Q$ and summing over the $N$ firms yields the industry supply relation

$$
p=\frac{H(1+\theta)}{\eta}+\sum_{i} \sum_{k} \alpha_{i k}\left(\nu_{i} \nu_{k}\right)^{1 / 2}+2 H Q \sum \beta_{i} \nu_{i}
$$

\footnotetext{
${ }^{2}$ In 1977, for instance, $82.5 \%$ of all shipments were within a radius of 200 miles, $99.8 \%$ were for distances shorter than 500 miles (US Department of Commerce, 1977).

${ }^{3}$ See, for example, Rosenbaum (1994) or Jans and Rosenbaum (1996).

${ }^{4}$ Portland Cement Association (1984).
} 
where $H=\sum_{j}\left(q_{j} / Q\right)^{2}$ is the Herfindahl Index and $\theta$ is the industry conjectural variation. Equation 5 states that, in equilibrium, output price is the sum of two components: an oligopoly component, as measured by the first term on the right hand side, and a marginal cost component, as measured by the last two terms. For a given $H$ and $\eta$ the magnitude of the oligopoly component depends on the type of oligopolistic behavior. The simplest type is Cournot. In this case $\theta=0$. The benchmark for an industry that is more competitive than Cournot is between zero and -1 , where a value of -1 implies price-taking behavior. The benchmark for one that is less competitive than Cournot is between 0 and the joint-profit maximizing value $1 / H-1$. Solving for the $j$ th firm's market share from Equation 3 yields

$$
\frac{q_{j}}{Q}=\frac{\eta}{1+\theta_{j}}\left(c_{j}-p\right)
$$

Following Clarke and Davies, summing Equation 6 over $N$, solving for $p$, substituting $p$ back into Equation 6 and summing its square yields the Herfindahl Index equation

$$
H=\frac{1}{N}+\frac{N \eta^{2} \sigma_{c}^{2}}{(1+\theta)^{2}}
$$

where $N$ is the number of firms in the industry, and $\sigma_{c}^{2}$ is the coefficient of variation of marginal costs. Assuming the demand Equation 1 takes the semilogarithmic form

$$
\ln Q=\alpha_{0}+\eta p+\underline{\alpha} Z
$$

the estimating model consists of Equations 5, 7 and 8.

The tradeoff between concentration-induced market power effects and cost-efficiency effects on price may be measured with a constant or variable $\theta$. If $\theta$ is assumed constant, differentiation of Equation 5 with respect to $H$, yields

$$
\frac{\partial p}{\partial H}=\frac{(1+\theta)}{\eta}+2 Q \sum \beta_{i} \nu_{i}
$$

Alternatively, if conduct is influenced by market concentration, as maintained in this paper, i.e., $\theta=\theta(H)$, the derivative becomes

$$
\frac{\partial p}{\partial H}=\frac{\left(1+\theta(H)+H \theta^{\prime}(H)\right)}{\eta}+2 Q \sum \beta_{i} \nu_{i}
$$

where the first term in both Equation 9 and Equation 10 is the concentration-market-power effect, and the second is the concentration-cost-efficiency effect. Finally, differentiation of Equation 7 with respect to $\sigma_{c}^{2}$ gives the effect of differential efficiency on concentration. The point estimate and standard error of the respective effects can be obtained using the econometric estimates from the joint model.

\section{Empirical Application}

Assuming the conduct parameter $\theta$ is a linear function of the Herfindahl index (Rosenbaum), the empirical counterparts of Equations 5, 7 and 8 are respectively,

$$
\begin{aligned}
\text { rprice }= & -\frac{\text { herf }\left(1+\theta_{0}+\theta_{1} \text { herf }\right)}{d_{1}}+a_{11} \text { rpelec }+a_{22} \text { rpfuel } \\
& \left.+a_{33} \text { rwage }+2 \text { herf.shipment }\right) \\
& \times\left(\beta_{1} \text { rpelec }+\beta_{2} \text { rpfuel }+\beta_{3} \text { rwage }\right)+e_{1} \\
\text { herf }= & \frac{1}{\text { nfirm }}+\frac{\text { nfirm }\left(d_{1}\right)^{2} \cdot \text { varcost }}{\left(1+\theta_{0}+\theta_{1} \text { her } f\right)^{2}}+e_{2}
\end{aligned}
$$

and

$$
\begin{aligned}
\ln \text { shipment }= & d_{0}+d_{1} \text { rprice }+d_{2} r h w y \\
& +d_{3} r n h w y+d_{4} r p a s p h+e_{3}
\end{aligned}
$$

The $\theta^{\prime} \mathrm{s}, \alpha$ 's, and $d^{\prime} \mathrm{s}$ are parameters to be estimated, and the $e$ 's are error terms. In Equation 11, the variables rprice, rpelec, rpfuel, rwage, and shipment are respectively, the real price of cement, the real price of electricity, the real price of fuel, the real hourly wage adjusted for productivity, and quantity of cement shipped. Note that the fixed proportions assumption leads to no cross products on the input prices for the cost part of Equation 11. In Equation 12, the variable nfirm represents the number of firms, and varcost the variance in costs across firms. In the demand Equation 13, rhwy, rnhwy, and rpasph are, respectively, real highway construction expenditures, real nonhighway construction expenditures, and the real price of asphalt . Precise definition of the variables and their sources are in the Appendix. Mean, minimum, and maximum values of variables are shown in Table 1.

Using Equation 10, and denoting by mpe the market power effect, and by efe the cost-efficiency effect, we now have

Table 1. Means and ranges for variables used in estimation, $N$ $=321$

\begin{tabular}{lccc}
\hline Variable & Mean & Minimum & Maximum \\
\hline rprice & 50.803 & 29.384 & 73.842 \\
herf & 0.2615 & 0.0773 & 1.000 \\
shipment & 3226.82 & 668.48 & 8025.20 \\
nfirm & 6 & 1 & 15 \\
rpelec & 12.9962 & 2.3002 & 21.240 \\
rpfuel & 2.0617 & 1.1651 & 2.9675 \\
rwage & 0.1169 & 0.0629 & 0.1708 \\
rhwy & 1760.06 & 6.0024 & 757.6888 \\
rnhwy & 3.7472 & 265.3200 & 757.6888 \\
rpasph & 3.7472 & 2.4728 & 5.8504 \\
varcost & 43327.95 & 0 & $278,784.0$ \\
\hline
\end{tabular}


Table 2. Summary of model estimates and standard errors

\begin{tabular}{lccc}
\hline Item & Parameter & Estimate & Standard error \\
\hline Price equation: & $\theta_{0}$ & $31.492^{\mathrm{a}}$ & 9.422 \\
& $\theta_{1}$ & $-32.475^{\mathrm{a}}$ & 9.558 \\
& $\alpha_{11}$ & 0.186 & 5.984 \\
& $\alpha_{22}$ & -117.317 & 111.622 \\
& $\alpha_{33}$ & -1160.360 & 1511.5 \\
& $\beta_{1}$ & $-0.014^{\mathrm{b}}$ & 0.005 \\
& $\beta_{2}$ & 0.105 & 0.092 \\
& $\beta_{3}$ & -1.521 & 1.189 \\
Mean conjectural variation: & $\theta=\theta_{0}+\theta_{1} h e r f$ & $22.999^{\mathrm{a}}$ & 6.934 \\
Demand equation: & $d_{0}$ & $8.803^{\mathrm{a}}$ & 0.130 \\
& $d_{1}$ & $-0.009^{\mathrm{a}}$ & 0.002 \\
& $d_{2}$ & $0.0004^{\mathrm{a}}$ & 0.0001 \\
& $d_{3}$ & $0.00004^{\mathrm{a}}$ & 0.00001 \\
Market-power effect: & $d_{4}$ & $-0.094^{\mathrm{a}}$ & 0.0189 \\
Cost-efficiency effect: & $m p e$ & $1809.59^{\mathrm{a}}$ & 33.701 \\
Total effect: & efe & $-908.499^{\mathrm{a}}$ & 124.022 \\
Efficiency-concentration effect: & mpe + efe & 901.091 & 128.902 \\
\hline Notes: a = Statistically significant at the 99\% level. & $8 E-7^{\mathrm{a}}$ & $5 E-8$ \\
\hline
\end{tabular}

$\mathrm{b}=$ Statistically significant at the $95 \%$ level.

$$
\text { mpe }=-\frac{\left(1+\theta_{0}+2 \theta_{1} \text { herf }\right)}{d_{1}}
$$

and

$$
\text { efc }=2 \text { shipment }\left(\beta_{1} \text { rpelec }+\beta_{2} r p f u e l+\beta_{3} r w a g e\right)
$$

From Equation 7, the differential efficiency effect (dee) is

$$
\text { dee }=\frac{\partial H}{\partial \sigma_{c}^{2}}=\frac{n f \text { irm }\left(d_{1}\right)^{2}}{\left(1+\theta_{0}+\theta_{1} \text { herf }\right)^{2}}
$$

\section{Results}

Results of the analysis are shown in Table 2. The first group of parameters is for the price equation. The first two parameters in this group are used to form $\theta$, the conjectural variation measure. Results for the linear specification are $\theta=31.492-32.475$ herf. The mean conjectural variation is about 23 and is highly significant. The conjectural variation is also statistically greater than zero for all values of the Herfindahl Index below 0.90 . This holds for all but two observations in the sample. Apparently conjectures are more collusive than Cournot.

The $\alpha_{i k}^{\prime}$ 's and $\beta^{\prime} i^{\prime}$ s in Table 2 form the marginal cost part of the price equation. Only $\beta_{1}$ is statistically significant by itself. However, since the industry marginal cost function is a complex aggregation of the underlying firm-level marginal cost functions, it is difficult to exactly interpret the meaning of these parameters. Parameter estimates do suggest that marginal costs are un- ambiguously increasing in fuel costs. ${ }^{5}$ Since fuel is the predominant input, this result is reassuring.

The second group of parameters in Table 2 is for the demand equation. These results are more easily interpreted. Demand is downward sloping in price. The parameter $d_{1}$ is the semidemand-elasticity. (Recall that $d_{1}$ $=(\mathrm{d} Q / \mathrm{d} P) \times(1 / Q))$. If the full elasticity is calculated by multiplying $d_{1}$ by the mean of price, the resulting elasticity is 0.45 , well in the inelastic range. This is a reasonable result. Demand is increasing in both highway and nonhighway construction expenditures. It is decreasing in the price for the substitute input, asphalt. This final result is contrary to expectation. However, as Rosenbaum points out, the price of asphalt may be proxying for general fuel costs.

The bottom part of the Table 2 contains the results that are the main focus of this analysis. The MarketPower Effect, mpe, measures the impact that concentration-induced changes in market power have on price. This effect is positive and significant. When concentration (as measured by the Herfindahl Index) increases, prices will increase as a result of the implied increase in market power. The coefficient on mpe is 1810. Multiplying by herf/rprice when both are evaluated at their mean values gives an approximation of an elasticity that measures relative changes in price associated with relative changes in market power. This elasticity is roughly 9.0, suggesting that every $1 \%$ increase in the Herfindahl Index increases prices by about $9 \%$ due to changes in market power.

The Cost Efficiency Effect, efe, measures the impact that concentration-induced changes in efficiency have

\footnotetext{
${ }^{5}$ The derivative of marginal cost with respect to the price of input $i$ is $\partial c_{j} / \partial v_{i}=\alpha_{i i}+2 H Q \beta_{i}$.
} 
on price. This effect is negative and significant. When concentration increases, prices decrease as a result of the implied greater production efficiency. This result is reasonable in cement markets since larger firms are associated with larger kilns which benefit from economies of scale and more efficient technologies. The coefficient on efe is -908. Multiplying by the mean of herf/price gives an elasticity that measures relative changes in price associated with relative changes in cost efficiency. The elasticity equals -4.5 ; suggesting that every $1 \%$ increase in the Herfindahl Index decreases prices by about $4.5 \%$ due to increases in market efficiency.

Comparing the two impacts, the efficiency effect is about half as great as the market power effect. Combining the efficiency and market power effects, the overall coefficient of change in price with a change in the Herfindahl Index is 901 and statistically significant. The overall elasticity measuring the relative change in price associated with relative changes in the Herfindahl Index is 4.5. When the price lowering effects of increased efficiency are combined with the price rising effects of increased market power, the overall impact is that every $1 \%$ increase in the Herfindahl Index increases prices by about $4.5 \%$.

The last estimate in Table 2 shows the differential efficiency effect. This measures the change in the Herfindahl Index with a change in the variance in costs across firms in the market. The coefficient is positive and statistically significant, but it is fairly small at 8E-7. However, the elasticity at the mean is about 0.13 , suggesting that a $7.7 \%$ increase in cost variance increases the Herfindahl Index by 1\%. Table 1 shows that the maximum of the cost variance measure is more than six times the mean. Hence, there can be fairly large disparities in cost variance across markets and, as a result, fairly large disparities in concentration.

\section{VI . Conclusion}

A persistent question in industrial economics is the underpinning of the link between market concentration and price. Does market power increase price or does market efficiency reduce it? This paper develops a theoretical model to examine that link. It advances a model that separates concentration into a market power component and an efficiency component. The model is parameterized and applied to the US portland cement industry. The results indicate that both impacts matter. When changes in concentration enhance market power, it leads to higher prices. When changes in concentration enhance relative efficiency, it leads to lower prices. In relative terms, however, the market power effect is twice as large as the efficiency effect. Hence, when concentration increases, prices rise. These results will create a dilemma for merger policy. Apparently the beneficial efficiency effects of mergers are outweighed by the detrimental market power effects.

\section{References}

Appelbaum, E. (1982) The estimation of the degree of oligopoly power, Journal of Econometrics, 9, 287-99.

Azzam, A. (1997) Measuring market power and cost efficiency effects of industrial concentration, Journal of Industrial Economics, 377-86.

Bresnahan, T. F. (1982) The oligopoly solution is identified, Economic Letters, 10, 87-92.

Clarke, R. and Davies, S. (1982) Market structure and price-cost margins, Economica, 49, 277-87.

Clarke, R., Davies, S., and Waterson, M. (1984) The profitabilityconcentration relationship: Market power or efficiency, Journal of Industrial Economics, 32, 435-50.

Demsetz, H. (1973) Industry structure, market rivalry, and public policy, Journal of Law and Economics, 16, 1-10.

Diewert, W. E. (1971), An application of the Shephard duality theorem: A generalized Leontief production function, Journal of Political Economy, 79, 481-507.

Jans, I., and Rosenbaum, D. I. (1996) Multimarket contact and pricing: Evidence from the US cement industry, International Journal of Industrial Organization, 15, 391-412.

Kardasz, S. W., and Stollery, K. R. (1995) Efficiency versus collusion: a reformulation of the Weiss test, Applied Economics, 27, 539-45.

Kwoka, J. E. (1979) The effect of market share distribution on industry performance, Review of Economics and Statistics, 61, 101-9.

Philips, A. (1976) A critique of empirical studies of relations between market structure and profitability, Journal of Industrial Economics, 24, 241-9.

Portland Cement Association (1984) The US Cement Industry, An Economic Report, PCA, Skokie, IL.

Portland Cement Association (various years) Plant Information Summary, Skokie, IL.

Portland Cement Association (various years) Energy Report, Skokie, IL.

Ravenscraft, D. J. (1983) Structure-profit relationship at the line of business and industry level, Review of Economics and Statistics, 65, 22-31.

Rosenbaum, D. I. (1994) Efficiency v. collusion: evidence cast in cement, Review of Industrial Organization, 9, 379-92.

US Department of Commerce (1977a) Census of Transportation, US Government Printing Office, Washington, DC.

US Department of Commerce (1977b) Construction Review, US Government Printing Office, Washington, DC.

US Department of Commerce (various years) City Government Finances, US Government Printing Office, Washington, DC.

US Department of Commerce (various years) Housing Authorized by Building Permit and Public Contracts, City Government Finances, US Government Printing Office, Washington, DC.

US Department of Commerce (various years) Statistical Abstracts of the United States, US Government Printing Office, Washington, DC.

US Department of Energy (various years) Energy Price and Expenditure Data Report, US Government Printing Office, Washington, DC.

US Department of Interior (various years) Mineral Yearbook, US Government Printing Office, Washington, DC.

US Department of Labor (various years) Employment Hours and Earnings, States and Areas, 1972-1987, US Government Printing Office, Washington, DC.

Williamson, O. (1968) Economies as an antitrust defense: the welfare tradeoff, American Economic Review, 58, 18-36. 


\section{Appendix}

The analysis examines data from 25 metropolitan markets over the period 1972 through $1989 .{ }^{6}$ Each of the metropolitan markets consists of a major metropolitan area and all Portland cement plants located within 200 miles of the central city.

The Portland Cement Association (PCA), in its Plant Information Summary, provides the following information for practically all cement plants in the USA: plant location, the year when kilns at a plant were constructed, kiln capacity, and the technology used by each kiln. These data provide the basis for calculating most of the necessary variables.

Price (rprice) The US Department of the Interior in its Minerals Yearbook publishes data on the value and volume of cement shipped, aggregated to either states or subregions of states. Dividing value by volume gives a transaction price. A market price is then calculated for each metropolitan market in each year by weighting the price in each state within the market by the percentage of the market's capacity located in that state. The average price is then deflated by the Producer Price Index (PPI) with 1982 as a base year to obtain an estimate of the real transaction price per ton of cement. ${ }^{7}$

To obtain the capacity weights, data from the PCA's Plant Information Summary are used. From these data (described above), the percentage of a market's capacity located within each state can be determined. These percentages become the weights in converting all statelevel data to market-level data.

Shipments (shipment) The US Department of the Interior, in its Minerals Yearbook, also publishes data on kiln capacities by region. For each Minerals Yearbook region, the volume of shipments is divided by capacity to obtain a shipments-to-capacity ratio. The PCA data are then used to form metropolitan market shipment to capacity ratios. For each market, the Minerals Yearbook shipmentsto-capacity ratio is multiplied by the PCA market capacity to get a measure of market shipments in millions of tons. Finally, imports are added to get total shipments.

Real Highway Construction Expenditures (rhwy) Highway construction expenditures, in current dollars, for each metropolitan market can be obtained from the US Department of Commerce, Bureau of the Census's City Government Finances. They are deflated by the PPI to obtain real values in millions of dollars.

Real NonHighway Construction Expenditures ( $\mathrm{rn}$ $h w y)$ Nonhighway expenditures are the sum of residen- tial and nonresidential, nonhighway construction expenditures. Current dollar new residential construction expenditures, by city, are published by the US Department of Commerce, Bureau of the Census in Housing Authorized by Building Permits and Public Contracts. Current dollar nonresidential, nonhighway construction expenditures, by city, are published in the US Department of Commerce, Bureau of the Census's Construction Review. The two values are summed and deflated by the PPI to produce annual real values in millions of dollars.

Real Price of Asphalt (rpasph) State-level asphalt prices, in dollars per million Btu, are obtained from the Energy Price and Expenditure Data Report published by the US Department of Energy. The state-level data are weighted by relative kiln capacities to get metropolitan market data. These are deflated by the PPI to get real values.

Real Price of Electricity (rpelec) State-level electricity prices for the industrial sector, in dollars per million Btu, are obtained from the Energy Price and Expenditure Data Report published by the US Department of Energy. The state-level data are weighted by relative kiln capacities to get metropolitan market data. These are deflated by the PPI to get real values.

Real Wage (rwage) State-level average hourly wages for nonsupervisory workers in all manufacturing industries are obtained from the US Department of Labor's Employment Hours and Earnings. The metropolitan region real wage rate is derived by weighting the state level data by the share of the kiln capacity located in each state, then deflated by CPI. This real wage is adjusted by the national cement output index to reflect the change in the average productivity of labor over time.

Real Price of Fuel (rpfuel) Cement manufacturers predominantly use either coal or natural gas as kiln fuels. In 1979, for example, $92.8 \%$ of fuel was either coal or natural gas (PCA, Energy Report, 1980). State-level prices for both coal and natural gas, in dollars per million Btu, are obtained from the Energy Price and Expenditure Data Report published by the US Department of Energy. They are then weighted by relative kiln capacities to get metropolitan market data. The PCA's Energy Report shows the yearly national relative use of coal and natural gas as kiln fuels. The metropolitan market prices for each type of fuel are weighted by their yearly respective uses to calculate fuel prices per million Btu. These are deflated by the PPI to get real values.

\footnotetext{
${ }^{6}$ The cities are Atlanta, Baltimore, Birmingham, Boston, Chicago, Cincinnati, Cleveland, Dallas, Houston, San Antonio, Denver, Detroit, Kansas City, Los Angeles, San Francisco, Minneapolis, New Orleans, New York City, Oklahoma City, Philadelphia, Phoenix, Pittsburgh, St. Louis, Salt Lake City and Seattle.

${ }^{7}$ The Producer Price Index data are from The Statistical Abstract of the United States (US Department of Commerce), various issues.
} 
Herfindahl Index (herf) The Herfindahl Index is a capacity-based Herfindahl index. The capacity-based market shares are derived from PCA Plant Information Summary data.

Number of Firms (nfirm) This is the number of firms in a market in any particular year as measured from the PCA Plant Information Summary.
Variance in Costs (varcost) Costs are assumed to vary as a function of kiln size. Larger kilns tend to be newer, benefit from scale economies and use more efficient technologies. The variance in costs is proxied by the variance in kiln size in a market in any particular year. Kiln sizes in millions of tons are obtained from the PCA Plant Information Summary. 